\title{
Controvérsias sobre Vacinas: o que pensam
} os estudantes?

Gleice Prado Lima*, Adjane da Costa Tourinho e Silva**, Divanizia do Nascimento Souza**

\section{Resumo}

A vacina é um marco na história da humanidade, pois sua eficácia garantiu que diversas doenças fossem erradicadas. Entretanto, é perceptível que o número de pessoas que buscam a imunização vem decaindo, fazendo com que doenças, como o sarampo, ressurjam. Com o intuito de engajar alunos em práticas que favorecem o processo de Alfabetização Científica, este trabalho buscou analisar a construção de argumentos elaborados por alunos do $1^{\circ}$ ano do Ensino Médio nas aulas de Biologia, por meio de uma sequência de ensino investigativa baseada no tema vacina, já que temáticas que envolvem o enfoque científico e social mostram aos alunos como ocorre a integração ciência, tecnologia e sociedade. A análise dos discursos orais dos alunos evidencia o surgimento de ricos debates sobre o tema. Todavia, os textos escritos de alguns evidenciam argumentos controversos, em que refutadores se opõem completamente às conclusões. Verificou-se ainda argumentos semelhantes aos divulgados em canais de informação, em que a vacinação é apresentada como decisão individual.

Palavras-chave: Ensino de Biologia. Argumentação. Sequência de Ensino Investigativa. Vacinas.

\footnotetext{
- Mestra em Ensino de Ciências e Matemática e Licenciada em Ciências Biológicas pela UFS. Docente do Colégio Rezende (Nossa Senhora da Glória - SE, Brasil), atuando nas disciplinas de Ciências e de Biologia. E-mail: gleicepl.biologia@gmail.com

* Doutora em Educação pela UFMG, Mestre em Educação e Licenciada em Química pela UFS. Professora titular aposentada da UFS e docente permanente do Núcleo de Pós-Graduação em Ensino de Ciências e MatemáticaUFS e da Rede Nordeste de Ensino (RENOEN). E-mail: adjane@acadêmico.ufs.br

.*- Doutora em Tecnologia Nuclear pela USP e Mestre em Física pela UFS. Docente do Departamento de Física da UFS e docente permanente do Núcleo de Pós-Graduação em Ensino de Ciências e Matemática da UFS e da Rede Nordeste de Ensino (RENOEN). E-mail: divanizi@ufs.br
} 


\section{Introdução}

A utilização de métodos de imunização para que o organismo humano adquira resistência aos patógenos é datada desde o século XI na China e na Ásia. Entretanto, somente no século XVIII, com os estudos e experimentos realizados pelo médico inglês Edward Jenner, é que estes métodos ganham notoriedade e a vacina passa a ser legitimada como uma técnica segura, que garante a prevenção e erradicação de doenças (TOLEDO, 2005).

Os estudos de Jenner, por mais de 20 anos, foram motivados pelo grande número de mortes causadas pela varíola, uma doença infectocontagiosa, decorrente de infecções pelo vírus Orthopoxvirus variolae, que se caracteriza pela presença de pústulas na pele. Considera-se a imunização descoberta por Jenner como um dos mais importantes avanços da medicina (TOLEDO, 2005; LEVI; KALLÁS, 2019).

Vacinas são compostos biológicos produzidos por meio de partículas do próprio agente agressor ou que apresentam informação genética deste que, ao adentrarem no organismo, estimulam a formação de anticorpos, os quais atuam na proteção contra determinada patologia (DINIZ; FERREIRA, 2010). Historicamente, tem-se constatado que o seu uso vem sendo responsável pela erradicação de doenças que dizimaram populações. No entanto, atualmente, as polêmicas envolvendo a administração das vacinas vêm motivando na população recusa à este mecanismo de defesa. Entre os motivos de recusa destacam-se fatores religiosos, filosóficos, políticos, familiares, bem como as reações adversas em alguns indivíduos após sua administração (PONCE-BLANDÓN et al., 2018; CUNHA; GARCIA, 2019).

Essa polêmica tem se instaurado em distintos momentos históricos, haja vista a resistência da população em relação à vacinação contra a varíola, no século XVIII na Inglaterra (HOCHMAN, 2011) e, mais recentemente, no Brasil. No início do século XX, a população do Rio de Janeiro sofreu com as epidemias de peste, varíola e febre amarela, doenças essas que só foram erradicadas devido aos atos violentos e autoritários do poder público, pois a população rejeitava a exposição de partes do seu corpo para a inoculação da vacina e os pedidos de higienização domiciliar feitos pelo sanitarista Oswaldo Cruz (PORTO, 2003; PORTO; PONTE, 2003).

Diante de tantas resistências ao uso da vacina, movimentos denominados antivacinas, ganharam força e, de alguma forma, banalizam o processo de vacinação, causando impactos na vida em sociedade, visto que surtos de doenças consideradas 
erradicadas no Brasil e em outros países, a exemplo do sarampo, vêm ressurgindo (SANCHES; CAVALCANTI, 2018; PONCE-BLANDÓN et al., 2018).

No contexto escolar, quando analisados os conteúdos apresentados nos livros didáticos de Biologia do Ensino Médio, percebe-se que o tema vacina é tratado apenas na perspectiva da conceitualização, informando-se que se trata de um método de prevenção de doenças, correspondendo a um processo de imunização ativa, o qual envolve a produção de anticorpos.

As abordagens ao tema propostas nos livros didáticos na maioria dos casos não exploram os contextos histórico, social e científico que envolvem a produção e distribuição das vacinas, bem como não promovem um debate que articule o tema a aspectos tecnológicos e sociais da atualidade. $\mathrm{O}$ foco das atenções neste tipo de ensino é no conteúdo conceitual, no aprender ciência de acordo com a discussão apresentada por Hodson (2014). Isso, certamente, não contribui para uma compreensão mais ampla sobre tal tema, na perspectiva de formação da cidadania dos alunos.

Um ensino que se desenvolva em prol da Alfabetização Científica tem sido defendido nas últimas décadas. De acordo com tal paradigma, busca-se promover atividades de ensino que contemplem os seguintes eixos: (i) a compreensão básica de termos e conceitos científicos, retratando a importância de que os conteúdos curriculares próprios das ciências sejam debatidos na perspectiva de possibilitar o entendimento conceitual; (ii) a compreensão da natureza da ciência e dos fatores que influenciam sua prática, deflagrando a importância do fazer científico ocupar espaço nas aulas dos mais variados modos, desde as próprias estratégias didáticas adotadas, privilegiando a investigação em aula, passando pela apresentação e pela discussão de episódios da história das ciências que ilustrem as diferentes influências presentes no momento de proposição de um novo conhecimento; e (iii) o entendimento das complexas relações entre ciência, tecnologia, sociedade e ambiente, permitindo uma visão mais completa e atualizada da ciência, vislumbrando relações que impactam a produção de conhecimento e são por ela impactadas (SASSERON, 2015).

Na perspectiva da Alfabetização Científica, várias pesquisas que se voltam para o ensino de Biologia (SASSERON; CARVALHO, 2008; TRIVELATO; TONIDADEL, 2015; RATZ; MOTOKANE, 2016), vêm discutindo o potencial de atividades investigativas. Para Hodson (2014), a educação científica envolve quatro objetivos básicos de aprendizagem: aprender ciência, aprender sobre ciência, fazer ciência e aprender a abordar questões sociocientíficas (QSC). As atividades investigativas contemplam, 
de acordo com este autor, o terceiro objetivo, possibilitando aos alunos o engajamento nas práticas relativas à resolução de problemas científicos, desenvolvendo a confiança no confronto com situações do chamado mundo real.

Santos e El-Hani (2017), por sua vez, consideram que o fazer ciência pode ser visto como o objetivo primeiro da educação científica, como condição sine qua non para o alcance dos demais objetivos de aprendizagem. Partindo da perspectiva participacionista discursiva (SADLER, 2009), estes autores salientam que o fazer ciência pode ser entendido como participar do discurso científico. Assim, se aprender é mudar a forma de participação numa prática discursiva, para aprender o indivíduo precisa, primeiramente, estar participando dessa prática. Nesse sentido, o fazer ciência pode assumir diferentes formas, desde novas maneiras de usar conceitos e de combiná-los em teorias, incluindo novas habilidades em procedimentos e técnicas, até o uso de teorias, técnicas e procedimentos como ferramentas para a investigação científica.

Sendo assim, é recomendável que as aulas de Biologia prezem o ensino por investigação, a fim de favorecer o processo de Alfabetização Científica, fornecendo subsídios que auxiliem os alunos a compreender e discutir os significados construídos pela ciência, bem como os modos dessa produção.

$\mathrm{Na}$ construção de significados que emergem nas relações que se estabelecem por meio da linguagem no contexto da sala de aula, distintas práticas discursivas devem ser valorizadas. Dentre elas, a argumentação, adquire destaque, já que é por meio de um processo argumentativo que as conclusões oriundas de uma investigação são legitimadas, bem como distintos pontos de vista são contrapostos e avaliados. Isso certamente auxilia a aprendizagem dos alunos acerca da Natureza da Ciência, bem como na tomada de decisão diante de questões sociocientíficas (QSC) (ROCHA; SILVA, 2019). Portanto, a promoção de atividades que fomentem o desenvolvimento da habilidade argumentativa no ensino de Biologia tem o potencial de favorecer a compreensão de aspectos da cultura científica e suas relações com questões tecnológicas e sociais.

Segundo Driver, Newton e Osborne (2000), nas aulas de Ciências pouco se tem promovido a argumentação e, por conta disso, há um favorecimento da falsa impressão que a ciência é feita por meio de fatos não problematizados, de forma que existam apenas respostas corretas, sem controvérsias às questões científicas. Esse 
aspecto faz com que os alunos se limitem a incorporar as alegações científicas e as confrontem com suas experiências cotidianas.

Como são poucas as iniciativas que promovem de maneira investigativa a construção dos conteúdos de Biologia, buscamos a partir deste trabalho criar um ambiente de aprendizagem em que os estudantes utilizassem os conhecimentos científicos construídos para elaborar argumentos diante de QSC, julgando os dados empíricos obtidos de suas investigações, bem como os teóricos, dispostos na literatura.

Assim, no trabalho que aqui apresentamos, as vacinas e as controvérsias em torno da vacinação foram o eixo central de uma sequência de ensino de natureza investigativa desenvolvida em uma turma de $1^{\circ}$ Ano do Ensino Médio, em aulas da disciplina Biologia, em que foram valorizadas as interações discursivas e os argumentos elaborados por 17 alunos. A análise focalizou o processo argumentativo, de modo a avaliar a estrutura e o conteúdo dos argumentos orais e escritos ao longo da Sequência de Ensino Investigativa (SEI).

\section{padrão de argumento de Toulmin}

Para a identificação dos argumentos produzidos ao longo da SEI, foram considerados os elementos do Padrão de Argumento de Toulmin (2006). Essa ferramenta analítica apresenta subsídios que favorecem o reconhecimento de elementos lógicos específicos em argumentos de diferentes interlocutores (VIEIRA; NASCIMENTO, 2008).

Originado para estudos no campo jurídico, o padrão de argumento de Toulmin tornou-se bastante difundido em outros domínios, tais como Comunicação, Filosofia e Didática das Ciências. De acordo com tal padrão, os elementos estruturais fundamentais de um argumento são: o dado (D), a conclusão (C) e a garantia de inferência (G). A estrutura básica de um argumento é, portanto: a partir de um dado $D$, já que $G$, então $C$.

A conclusão (C) é a asserção que se busca defender; o dado (D) representa os fatos aos quais recorremos como fundamento para a asserção; e a garantia de inferência (G) estabelece as relações entre os dados e a conclusão. Para Toulmin, não há argumento sem garantia de inferência, visto que argumentar é justificar um dado ponto de vista. Nesse sentido, considera-se, em várias pesquisas no Ensino 
de Ciências, a possibilidade de garantia de inferência implícita quando esta não aparece explicitamente na passagem dos dados à conclusão.

De acordo com o Padrão de Argumento de Toulmin (2006), é possível apresentar um argumento com apenas estes elementos: Dado, Conclusão e Garantia de Inferência. Porém, para que um argumento seja completo, podem ser acrescentados qualificadores modais (Q), que são especificações das condições necessárias para que uma dada garantia (também chamada, por alguns autores, de justificativa) seja válida. Da mesma forma, é possível especificar em que condições a justificativa não é válida ou suficiente para dar suporte à conclusão. Neste caso, é apresentada uma refutação $(\mathrm{R})$ da justificativa.

Além dos elementos já citados, a garantia de inferência (G), que apresenta um caráter hipotético, pode ser apoiada em uma alegação categórica baseada em uma lei, por exemplo. Trata-se de uma alegação que dá suporte à tal garantia, denominada backing ou conhecimento de base (B). Portanto, B consiste em uma afirmativa baseada em alguma autoridade, uma lei jurídica ou científica, por exemplo, que fundamenta a garantia de inferência. Na figura 1 apresentamos a estrutura de argumento proposta por Toulmin (2006):

Figura 1: Padrão do Argumento de Toulmin (Adaptado de Toulmin, 2006, p.150)

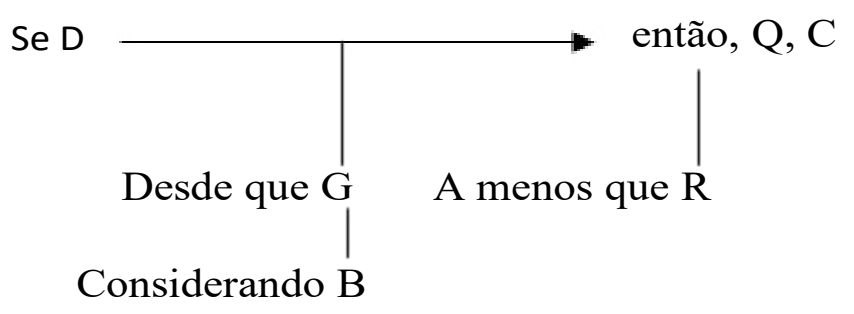

Fonte: Toulmin (2006, p.150).

\section{Metodologia}

Esta pesquisa é de natureza qualitativa, do tipo estudo de caso. De acordo com Ludke e André (1986), no estudo de caso se enfatiza a interpretação e descrição detalhada do contexto no qual estão inseridos os objetos e/ou sujeitos da pesquisa, assim como permite generalizações naturalistas e representa diferentes perspectivas presentes numa situação social. 
A Sequência de Ensino Investigativa aplicada abordou o tema vacinas e teve como questão central: $O$ uso de vacina pode ser opcional? A SEI foi elaborada de acordo com a proposta de Pedaste et al. (2015) já que queríamos que a promoção das práticas explicativa e argumentativa no contexto da sala de aula ocorressem efetivamente.

Pedaste et al. (2015), com base em uma revisão de literatura sobre Ensino por Investigação, apresentam a proposta de um ciclo investigativo composto por etapas conectadas, as quais orientam os alunos para o desenvolvimento da aprendizagem e as principais características do pensamento científico. Por meio do desenvolvimento do ciclo investigativo, os alunos seguem métodos e práticas semelhantes aos dos cientistas, a fim de produzir conhecimentos que respondem às questões de investigação. $\mathrm{O}$ entendimento do ciclo investigativo possibilita ao professor perceber quais adaptações são necessárias ao longo do desenvolvimento das atividades, o que contribui para uma melhor aprendizagem dos alunos.

As fases do ciclo investigativo de Pedaste et al. (2015) são: orientação, conceitualização, investigação, conclusão e discussão (Figura 2), conforme definidas a seguir.

Orientação: Nesta fase, um problema é proposto pelo professor e, por meio da curiosidade do aluno, ocorre estimulação para que se reflita sobre ele. Nesse sentido, tal fase possibilita o levantamento das concepções prévias dos alunos.

Conceitualização: Consiste no processo de compreensão de conceitos pertencentes ao problema. Aqui, duas subfases são elencadas: questionamentos (formulação de questões instigadas) e hipóteses (formulação de prováveis respostas, tendo em vista conceitos retomados ou elaborados nesta fase). Deste modo, as hipóteses baseiam-se em justificativas teóricas variáveis.

Investigação: Nesta fase, a curiosidade do aluno é transformada em ação para que as questões elaboradas sejam respondidas. Trata-se do processo de planejamento de exploração ou experimentação, coleta de dados baseada no esquema de exploração ou experimental delineado e análise dos dados obtidos. Pode haver nesta fase, portanto, três subfases: exploração, experimentação e análise dos dados.

Conclusão: Nesta fase ocorre o processo de esboçar conclusões, comparando inferências baseadas nos dados com as hipóteses ou questões de pesquisa. 
Figura 2: Fases e subfases do ensino por investigação (Adaptado de Pedaste et al., 2015, p. 56)

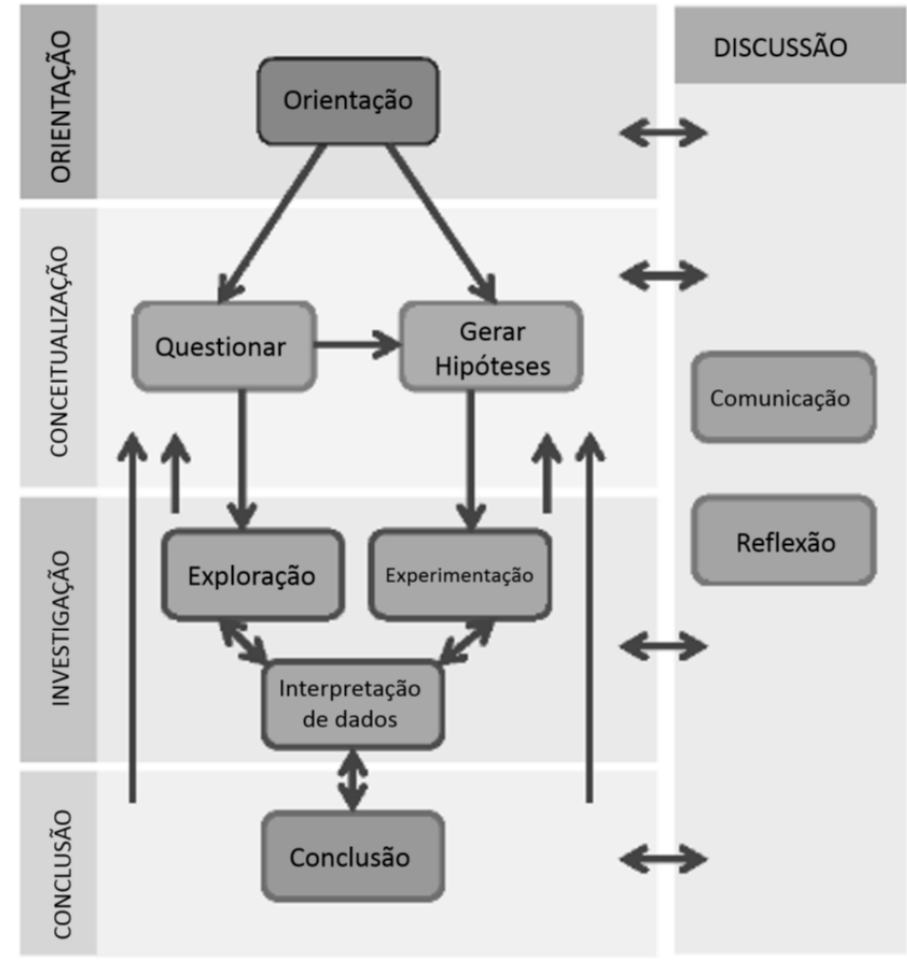

Fonte: Pedaste et al. (2015, p. 56).

Vale ressaltar que, em função da questão considerada, o ciclo investigativo pode envolver, em si mesmo, pequenos ciclos com questões e respostas específicas, sendo que estas últimas, em conjunto, irão responder à questão geral. Como apresentado no Quadro 1, a seguir, os encontros 2 e 3 envolveram pequenas investigações, em que dados experimentais foram informados por meio de textos, tratando de episódios da história da vacina, e submetidos à análise dos alunos, tendo em vista questões propostas no material didático. Nesse sentido, tais encontros envolveram mais de uma fase do ciclo. 
Quadro 1: Nomeação e descrição das fases da SEl utilizada no presente trabalho

\begin{tabular}{|c|c|c|}
\hline $\begin{array}{l}\text { Atividade(s) } \\
\text { Proposta(s) }\end{array}$ & Descrição das atividades & $\begin{array}{c}\text { Fases do Ciclo de } \\
\text { Pedaste et al. (2015) }\end{array}$ \\
\hline $\begin{array}{l}\text { Encontro } 1 \\
\text { Apresentando o } \\
\text { problema }\end{array}$ & $\begin{array}{l}\text { - Aplicação de questionário; } \\
\text { - Proposição do problema: "O uso de vacinas pode } \\
\text { ser opcional?" }\end{array}$ & Orientação \\
\hline $\begin{array}{l}\text { Encontro } 2 \\
\text { Entendendo a } \\
\text { história da vacina }\end{array}$ & $\begin{array}{l}\text { - Leitura de texto sobre a história da vacina no } \\
\text { mundo; } \\
\text { - Discussão das questões apresentadas ao longo } \\
\text { do texto; } \\
\text { - Análise dos dados dos experimentos realizados } \\
\text { por Edward Jenner para a produção da vacina } \\
\text { contra a varíola humana; } \\
\text { - Discussão dos resultados. }\end{array}$ & $\begin{array}{l}\text { Conceitualização } \\
\text { Investigação } \\
\text { Conclusão }\end{array}$ \\
\hline $\begin{array}{l}\text { Encontro } 3 \\
\text { Pasteur e as vacinas }\end{array}$ & $\begin{array}{l}\text { - Leitura do texto que ressalta o experimento de } \\
\text { Pasteur para a produção da vacina contra a cóle- } \\
\text { ra aviária; } \\
\text { - Discussão das questões apresentadas no texto; } \\
\text { - Análise dos dados dos experimentos realizados } \\
\text { por Pasteur; } \\
\text { - Discussão dos resultados. }\end{array}$ & $\begin{array}{l}\text { Conceitualização } \\
\text { Investigação } \\
\text { Conclusão }\end{array}$ \\
\hline $\begin{array}{l}\text { Encontro } 4 \\
\text { O uso de vacinas } \\
\text { pode ser opcional? }\end{array}$ & $\begin{array}{l}\text { - Exibição de vídeos que retratam diferentes pontos } \\
\text { de vista sobre as vacinas nos seres humanos; } \\
\text { - Discussão para elaboração de argumentos sobre } \\
\text { os vídeos exibidos; } \\
\text { - Elaboração de argumentos tendo em vista a } \\
\text { questão central da SEl; } \\
\text { - Discussão sobre o processo investigativo desen- } \\
\text { volvido ao longo da SEl. }\end{array}$ & $\begin{array}{l}\text { Conceitualização } \\
\text { Investigação } \\
\text { Conclusão }\end{array}$ \\
\hline
\end{tabular}

Os dados foram coletados por meio de gravações em áudio e vídeo das aulas e questionários aplicados ao longo da SEI. Os registros em áudio e vídeo foram armazenados em um computador e, posteriormente, transcritos. Após a transcrição, as aulas foram fragmentadas em episódios que passaram por um processo de seleção, visto que nem toda a fala produzida durantes os encontros traziam dados relevantes para a pesquisa.

Neste trabalho, são analisados os argumentos produzidos pelos alunos no Encontro 4, o qual tratou da questão central da SEI. Para a identificação e caracterização dos argumentos produzidos, foram considerados os elementos do modelo de Toulmin (2006). 


\section{Resultados e discussões}

No encontro 4, foram exibidos dois vídeos para que os alunos, ao final, expusessem seus argumentos sobre vacinação. $\mathrm{O}$ vídeo 1 , intitulado Pais que decidiram não vacinar seus filhos ${ }^{1}$, ressalta como pais no mundo inteiro estão utilizando outras práticas como método de prevenção de doenças. Nesse vídeo, são apresentadas, ainda, posições de especialistas que defendem a vacinação e questionam os grupos que se opõem a esse método de imunização. No vídeo 2 , intitulado Governo e médicos garantem que a vacina do HPV é segura ${ }^{2}$, é apresentado o drama de adolescentes que receberam a vacina do HPV e que, por algum motivo, tiveram reações adversas como paralisia cerebral e imobilidade, sendo que estas reações, passageiras, foram definidas pelos médicos como reações psicológicas.

O objetivo dessa atividade foi estimular o senso crítico dos alunos em torno da problemática do tema vacina, devido à resistência que vem crescendo na sociedade para a adesão a este método de imunização, embora esteja registrada e divulgada a sua importância ao longo dos séculos para a erradicação e prevenção de diversas doenças.

Optou-se pelo uso de vídeos disponibilizados na internet por se considerar que a utilização de recursos audiovisuais caracteriza práticas comunicativas e interativas da sociedade contemporânea, em que as ideias divulgadas por meio de tais recursos podem promover a formação de opiniões e comportamentos (PADILHA; SUTIL; MIQUELIN, 2013). Entendemos como importante que as aulas de ciências favoreçam o posicionamento dos alunos diante das informações disponibilizadas por tais meios de comunicação.

Após a visualização do vídeo 1 , os alunos foram solicitados a expor suas opiniões acerca dos seguintes questionamentos:1) Qual a opinião de vocês sobre essa prática de não vacinar os filhos? 2) Vocês acreditam que não vacinar pode gerar danos sociais? 3) Por que ainda existe resistência quanto ao uso da vacina? No quadro 2 estão transcritos alguns excertos da discussão que ocorreu após a exibição deste vídeo. Em tal quadro, o turno corresponde à fala de cada participante, a docente está indicada por Prof. e os alunos estão indicados pela letra A seguida de um número. 
Quadro 2: Excerto da discussão entre a professora e os alunos após visualização do vídeo 1.

\begin{tabular}{|c|c|}
\hline Turno & Transcrição \\
\hline 8 & $\begin{array}{l}\text { Prof. Bom como foi visto através do vídeo 1, muitos conceitos e aspectos já haviam sidos } \\
\text { discutidos nos encontros anteriores. Quem gostaria de ressaltar esses aspectos? A12, } \\
\text { qual a sua opinião sobre os pais que não vacinam seus filhos? }\end{array}$ \\
\hline 9 & $\begin{array}{l}\text { A12. Como já ressaltei em uma aula anteriormente, muitos pais não vacinam seus filhos } \\
\text { por diversos fatores, como por exemplo, religiosos e cultural, mas de certa forma esta } \\
\text { prática é errada, pois isso é conservadorismo. Logo, rsrs, continuo com a mesma opinião } \\
\text { relacionada ao uso opcional da vacina, ou seja, não deve ser opcional. }\end{array}$ \\
\hline 10 & Prof. Quem mais? Vamos dar a palavra a A14. \\
\hline 11 & A14. Eu professora? \\
\hline 12 & Prof. Sim, meu querido,você mesmo. Qual sua opinião? \\
\hline 13 & $\begin{array}{l}\text { A14. Eu acho que os pais que não vacinam não possuem conhecimento necessário para } \\
\text { tomar essa decisão. Porque se acontecer alguma coisa errada, sempre relaciona à vaci- } \\
\text { na. Muitos pais vão na internet e visualizam que a vacina faz mal, ai tomam a decisão de } \\
\text { não vacinar os filhos e não percebem o erro que estão cometendo. }\end{array}$ \\
\hline 14 & Prof. Mas que erros são esses? \\
\hline 15 & $\begin{array}{l}\text { A14. Ah professora... de deixar os filhos desprotegidos e com maior índice de pegar doen- } \\
\text { ças. }\end{array}$ \\
\hline 16 & $\begin{array}{l}\text { Prof. Me explique mais uma coisa. Por que apesar da eficácia da vacina comprovada } \\
\text { através de diversos experimentos, algumas pessoas não se habilitam a tomá-la? }\end{array}$ \\
\hline 17 & $\begin{array}{l}\text { A14. Eu conheço muitas pessoas que não utilizam dessa prática por conta do fator re- } \\
\text { ligioso. Na minha família tenho vários primos que não tomaram nenhuma vacina. Eles } \\
\text { utilizam outros métodos que se dizem eficazes. }\end{array}$ \\
\hline
\end{tabular}

É possível perceber nas transcrições do Quadro 2, a elaboração de argumentos. Os alunos A12 e A14 expressaram os diferentes pontos de vista de pais em relação ao processo de vacinação e como a falta de informação reflete-se na tomada de decisão das pessoas, que acabam não percebendo como a recusa à vacinação pode estimular o reaparecimento de doenças.

O argumento do aluno A12 apresenta como elementos estruturais: dado, conclusão e garantia de inferência, ou seja, os elementos fundamentais de um argumento como discutido por Toulmin (2006). Vejamos a Figura 3. 
Figura 3: Estrutura do argumento do aluno A12

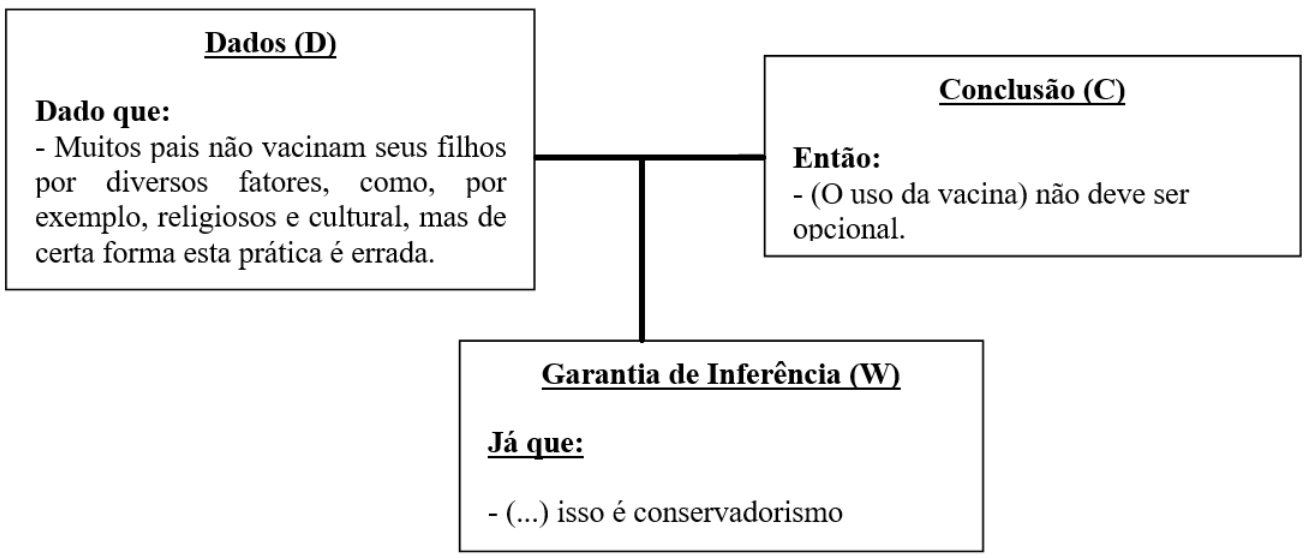

Fonte: Elaborada pelos autores.

Após a apresentação do dado, o aluno A12 (turno 9) concluiu que o uso da vacina não deve ser opcional. Ele expressou que a recusa à vacinação ocorre devido ao conservadorismo das ideias de uma parcela da população. Tal concepção funciona como garantia de inferência, uma vez que estabelece a relação entre o dado e a conclusão.

O aluno não explica o sentido atribuído ao termo conservadorismo mas, considerando-se o que foi discutido em aulas anteriores e ainda, que ele relaciona tal termo a aspectos culturais e religiosos, pode-se inferir que se refere ao fato de que várias pessoas, seguindo uma tradição, ainda optam pela imunização natural, ou seja, entendem que certas doenças não precisam ser evitadas, mas adquiridas para que ocorra uma imunização que evita a reincidência da doença no indivíduo, sem o uso de vacinas. $\mathrm{O}$ aspecto religioso relaciona-se a esse entendimento, já que a interferência humana nesse processo pode ser vista como oposição à divina.

O argumento de A14 (turno 13), por sua vez, apresenta como elementos estruturais dado e conclusão, como identificado na Figura 4 a seguir. Os dados expressam como a falta de conhecimento aliado à influência da divulgação de ideias em canais de informação, a exemplo das mídias online, favorecem a divergência na tomada de decisão quanto ao uso de vacinas. Assim, o aluno concluiu que esses fatores são propulsores para que os pais não vacinem seus filhos. 
Figura 4: Estrutura do argumento do aluno A14

\section{$\underline{\operatorname{Dados}(\mathrm{D})}$}

Dado que:

- Os pais que não vacinam não possuem conhecimento necessário para tomar essa decisão;

-Muitos pais vão na internet e visualizam que a vacina faz mal.

\section{Conclusão (C)}

Então:

- Tomam a decisão de não vacinar os filhos e não percebem o erro que estão cometendo.

Fonte: Elaborada pelos autores.

Os argumentos elaborados por ambos os alunos repassam a ideia de que muitos pais não possuem o conhecimento necessário sobre as implicações da não vacinação e acabam tomando decisões que prejudicam a prevenção de seus filhos contra diversas doenças, devido à falta de pensamento crítico acerca de hábitos arraigados e de notícias veiculadas na internet. Isso tem sido discutido em vários estudos reportados na literatura, a exemplo dos realizados por Sanches e Cavalcanti (2018) e Silva e Silva Junior (2019).

Um aspecto relevante que não é levado em conta na discussão transcrita no quadro 2 é o fato de que a decisão individual, de cada pai, resulta em consequência para toda a sociedade, uma vez que aumenta a probabilidade de disseminação de doenças. A vacinação até esse ponto está sendo discutida sem levar em conta a dimensão coletiva, social.

Em seguida, os alunos foram motivados a discutir sobre um dos métodos alternativos de imunização que vem ganhando destaque na sociedade como forma de prevenção de doenças, a homeopatia. Enquanto especialidade médica, a homeopatia passou a ser reconhecida pelo Conselho Federal de Medicina na década de 1980. Nos dias atuais, de acordo com a portaria 971/06 (BRASIL, 2006), a homeopatia é uma prática inserida na Política Nacional de Práticas Integrativas como forma de ampliar o acesso da população a serviços de atenção à saúde.

Na homeopatia não são recomendadas vacinas, mas sim o uso de medicamentos constituídos de substâncias de origem animal, vegetal ou mineral, diluídas e utilizadas na forma líquida, de glóbulos ou pó, por diversas vezes, de forma a possibilitar que os pacientes se tornem resistentes a algumas doenças e não sofram com prováveis efeitos colaterais decorrentes das vacinas (TEIXEIRA, 2010; SANTOS; 
MONTEIRO; VARGAS, 2018). Alguns homeopatas, como exibido no vídeo 1, são contrários à vacinação, devido às doses de antígenos que uma vacina contém. Essa dosagem passa a ser a vilã da história, por conta dos efeitos colaterais causados. Vejamos a discussão dos alunos sobre este conteúdo no Quadro 3, a seguir.

Quadro 3: Excerto da discussão acerca do uso da homeopatia como método de imunização.

\begin{tabular}{|c|c|}
\hline Turno & Transcrição \\
\hline 22 & $\begin{array}{l}\text { A8.Isso professora, a mulher no vídeo tem até carteirinha de vacinação homeopática. Mas } \\
\text { até que ponto o uso dessa prática pode garantir a imunização de uma pessoa? }\end{array}$ \\
\hline 23 & A3. Eu mesmo acho isso impossível! Fora que ela também falou da alimentação saudável. \\
\hline 24 & Prof. Mas por que você não concorda? \\
\hline 25 & $\begin{array}{l}\text { A3. Primeiro professora, hoje não existe alimentação saudável, tudo contém agrotóxico, } \\
\text { ninguém faz horta em casa para tirar todo o sustento. }\end{array}$ \\
\hline 26 & Prof. A5, você acha o quê? \\
\hline 27 & A5. Não sei que pergunta foi feita? \\
\hline 28 & $\begin{array}{l}\text { Prof. Mulher vamos lá, deixe te fazer a pergunta. O que você acha dos pais que utilizam } \\
\text { outras práticas, como por exemplo, a homeopatia como método de proteção e imunização } \\
\text { de doenças? }\end{array}$ \\
\hline 29 & $\begin{array}{l}\text { A5. Ah sim, eu acho que isso não garante } 100 \% \text { de imunização. Isso é uma prática recente, } \\
\text { que não se tem testes ou garantias que o filho não terá a doença. Isso da alimentação } \\
\text { também acho que não protege totalmente. Porque imagine se alimentação salvasse al- } \\
\text { guém, não teria o porque dos anticorpos reconhecerem os antígenos para criar memória } \\
\text { imunológica. Ao contrário, o estômago lá com suas enzimas é que seriam responsáveis } \\
\text { por nos proteger. }\end{array}$ \\
\hline
\end{tabular}

Na discussão apresentada no Quadro 3, notamos que o aluno A5 explicou a sua conclusão (turno 29) apresentando uma lógica de raciocínio em relação às garantias de eficácia das vacinas homeopáticas. A5 considera que não se tem garantias consistentes sobre a real eficácia e segurança de tais vacinas em relação às alopáticas, convencionais, expressando ainda que se trata de uma prática recente. Para ele, isso ocasiona um efeito negativo para o alcance da vacinação como política pública na imunização da sociedade contra doenças epidêmicas.

Outra característica apresentada no discurso do aluno A5 é a prática de alimentação saudável como garantia para a proteção contra doenças. Para o aluno, se isso fosse verídico, o sistema imunológico estaria em junção total com o sistema digestório, com células de defesa que garantissem que as pessoas não ficassem doentes. Essa resposta mostra que o aluno entende que existem alimentos que fortalecem $o$ sistema imunológico, assim como uma boa alimentação, mas que não são capazes 
de auxiliar na destruição de microrganismos do corpo. Vejamos abaixo, a estrutura do argumento de A5, de acordo com Toulmin (2006).

Figura 5: Estrutura do argumento do aluno A5

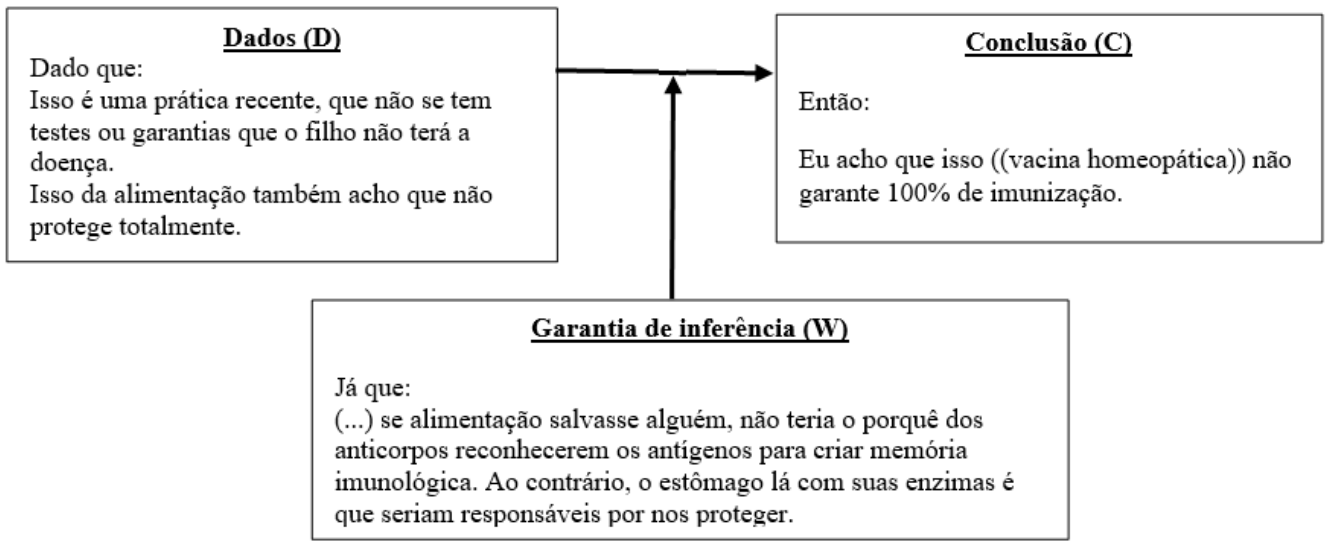

Fonte: Elaborada pelos autores.

A discussão sobre os princípios da homeopatia, os quais se contrapõem aos alopáticos, exigiria um investimento mais aprofundado em informações sobre esse tópico, o qual não foi explorado na aula pela professora. Seria oportuno abordar como a episteme homeopática e seus princípios para prevenção e cura de doenças geram certas dificuldades na elaboração de ensaios clínicos controlados que contemplem as premissas da metodologia científica clássica. Com relação à vacinação homeopática ser uma prática recente, há um equívoco por parte do aluno, já que a homeopatia data do século XVIII e constitui-se de práticas terapêuticas que visam estimular o organismo a reagir contra os seus próprios distúrbios (TEIXEIRA, 2010). Nesse sentido, seria efetivo, ainda, discutir como as políticas públicas se posicionam diante da vacinação homeopática, para que os alunos tivessem entendimento sobre tal fato e assim compreendessem os argumentos que sustentam a posição do Ministério da Saúde de garantir a obrigatoriedade da vacina (alopática) contra doenças epidêmicas.

Como dito inicialmente, no decorrer da aula foi exibido também o vídeo 2 , intitulado Governo e médicos garantem que a vacina do HPV é segura. Após a apresentação desse vídeo, buscamos obter dos alunos argumentos que expressassem a opinião deles acerca dos efeitos colaterais causados por algumas vacinas e da possibilidade de reações de ordem psicológica após a administração da vacina do HPV. Para isso, 
a professora questionou sobre até que ponto a reação às vacinas pode ser de ordem psicológica e não física. A partir do que está transcrito no Quadro 4, tem-se que os alunos defendem seus pontos de vista no debate utilizando dados obtidos dos meios de comunicação e de experiências próprias.

Quadro 4: Excertos da discussão sobre os efeitos colaterais das vacinas.

\begin{tabular}{|c|l|}
\hline Turno & \multicolumn{1}{c|}{ Transcrição } \\
\hline 65 & $\begin{array}{l}\text { Prof. E aí gente. Vocês acreditam que as pessoas podem ter reações psicológicas com } \\
\text { relação à vacina? O que vocês acham? }\end{array}$ \\
\hline 66 & $\begin{array}{l}\text { A13. Ai professora depende. Por exemplo, a vacina do HPV aqui no Brasil pelo menos a } \\
\text { terceira dose foi suspensa. Mas será que todas as reações adversas que muitas meninas } \\
\text { tiveram foram psicológicas? }\end{array}$ \\
\hline 67 & $\begin{array}{l}\text { A15. Isso mesmo. Porque eu vi na internet que umas meninas lá do Norte, não lembro } \\
\text { a cidade, ficaram paradas um monte de dia, sem andar nem nada, depois de tomarem a } \\
\text { vacina. Não acredito que foi psicológico. }\end{array}$ \\
\hline 68 & $\begin{array}{l}\text { Prof. Bom essa é uma questão que deve ser ponderada, já que reações adversas po- } \\
\text { dem ocorrer com qualquer medicação, mas também nosso medo pode nos levar a sentir } \\
\text { coisas. Num é? Por exemplo, às vezes alguém fala que se sentiu tão mal depois de } \\
\text { tomar um medicamento ou até mesmo uma vacina, que acabamos criando isso na nossa } \\
\text { cabeça, acreditando que seremos os próximos. Vamos lá. Quem aqui tomou vacina do } \\
\text { HPV e teve reação? }\end{array}$ \\
\hline 69 & A1. Eu não tive. \\
\hline
\end{tabular}

A discussão após a exposição do vídeo 2 possibilitou que a aula abordasse um aspecto comum aos medicamentos: os efeitos colaterais. As vacinas, como qualquer medicamento apresenta efeitos colaterais que podem variar em função do tipo de vacina e do sistema imunológico do indivíduo. Todavia, como as vacinas não são adquiridas pelas pessoas individualmente em farmácias, tal qual os remédios que apresentam uma bula com as informações adequadas, a população acaba, até certo ponto, alheia a variedade de efeitos colaterais e suas respectivas intensidades.

A discussão da turma na fase final do encontro, remeteu à questão problema da SEI, em que os alunos deveriam se posicionar sobre a opcionalidade da vacinação, justificando seus pontos de vista. Vale ressaltar que tal discussão envolve o fato de que há, dentre as várias vacinas existentes, aquelas que são obrigatórias de acordo com o Ministério da Saúde e que, portanto, devem ser acatadas por todos (BRASIL, 2014). Trata-se de vacinas para doenças infectocontagiosas que, geralmente, podem desencadear epidemias. Há outras, porém, que são legalmente opcionais e isso pode ser revertido para obrigatoriedade a depender da situação de uma população em dado momento em relação à certa doença. Enfim, quando tratamos da obrigatorie- 
dade e da opcionalidade da vacinação nos referimos à possibilidade de o indivíduo decidir sem interferência governamental.

Após análise das respostas, verificou-se que, do montante de 17 alunos que participaram desta atividade, $10(58,8 \%)$ consideraram possível a vacinação ser opcional, embora colocando ressalvas para tal, as quais se expressavam por meio de refutadores; $04(23,5 \%)$ defenderam a obrigatoriedade; $02(11,8 \%)$ não apresentaram uma posição concreta e 01 (5,9\%) não soube responder. Para uma melhor visualização dos argumentos separamos os alunos e suas respostas em grupos.

No Grupo 1 se inserem os alunos $(58,8 \%)$ que consideraram possível o uso opcional da vacina. Tendo em vista os elementos propostos no modelo do Argumento de Toulmin, observamos que nos argumentos desses alunos aparecem conclusões que remetem à opcionalidade do uso da vacina; porém, nota-se a presença de refutadores que estabelecem a ideia de vacinação pensada coletivamente, já que essa é uma questão social.

Quanto à estrutura dos argumentos, segue um exemplo na figura 6:

A3. Para mim, sim, pois as pessoas têm crenças diferentes em relação à medicina, têm religiões, logo deve ser opcional. Mas é necessário pensar coletivamente, já que vivemos em sociedade e temos que ter consciência para que as doenças não apareçam e contaminem outros indivíduos.

Figura 6: Estrutura do argumento do aluno A6

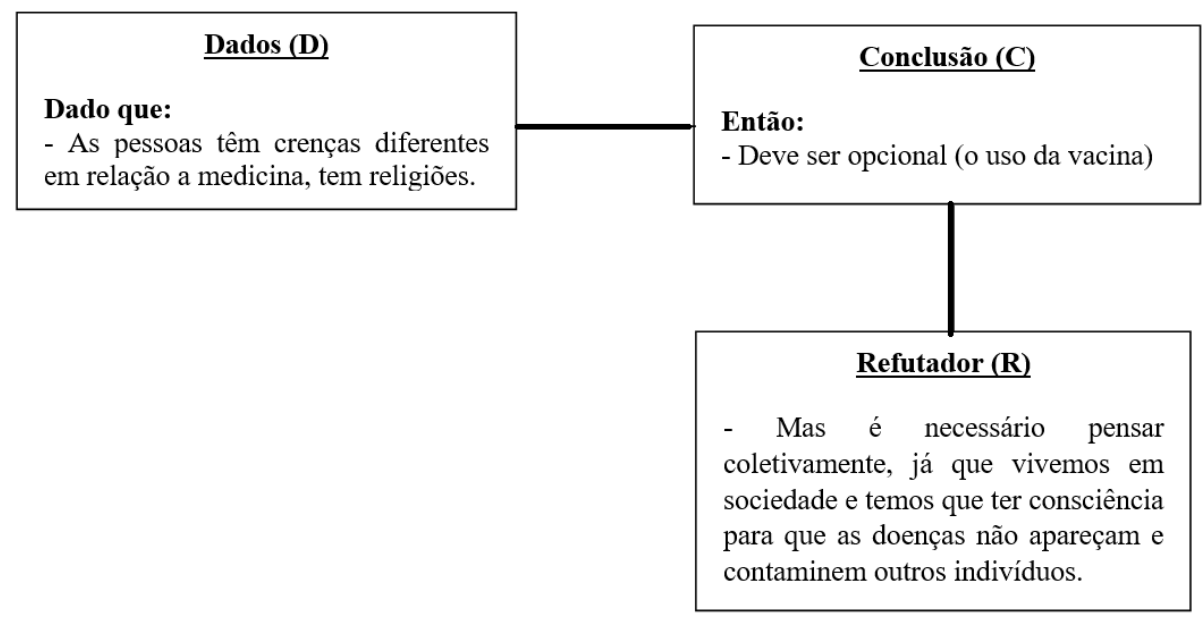

Fonte: Elaborada pelos autores. 
No argumento de A3, verifica-se que o dado expressa ideias expostas no vídeo e nas discussões ocorridas nas aulas relacionados às crenças que os indivíduos possuem. A partir desse dado, o aluno apresentou sua conclusão, expressando que o uso da vacina deve ser opcional. No entanto, o aluno refuta inteiramente a sua conclusão, ressaltando que essa decisão deve ser pensada coletivamente, já que a não vacinação pode possibilitar a disseminação de doenças. Esse refutador nos faz refletir sobre certa incoerência apresentada na resposta do aluno, pois ele concluiu que o uso da vacina deve ser opcional, mas ao mesmo tempo ressalta que essa decisão deve ser pensada coletivamente. Porém, essa dissonância entre conclusão e refutador não foi aprofundada no argumento.

Vale ressaltar que, a presença de refutadores seguindo essa linha de raciocínio, nos argumentos desse grupo, é algo considerado adequado do ponto de vista da mensagem que a SEI buscava promover aos alunos, pois há de se considerar que o uso de vacinas deve ser um bem coletivo.

Dados empíricos relacionados ao papel de cada indivíduo para erradicação de doenças poderiam ser mais explorados nas aulas a fim de se constituírem em elementos que fundamentassem melhor os argumentos de alguns dos alunos que se inseriram neste grupo 1, os quais apresentaram ideiam conflituosas entre si.

No Grupo 2 se inserem os alunos que defenderam que o uso da vacina não deve ser opcional (23,5\%). Quanto ao conteúdo, os alunos nas suas conclusões defenderam que o uso da vacina garante que as pessoas não contraiam doenças ao longo de suas vidas e, sobretudo, consideram a questão da vacinação levando em conta o aspecto coletivo, social.

Podemos verificar que no argumento de A12 (Figura 7) os dados expressam que a vacinação é a forma mais eficaz de se proteger contra doenças, mesmo com o aparecimento dos efeitos colaterais. Com base nessas ideias, ele conclui que apesar de todo embate existente na sociedade, o uso da vacina não deve ser opcional, já que se trata de uma questão pública e de saúde. Entretanto, como proposto pelo refutador, questões religiosas e culturais podem influenciar na tomada de decisão.

A12. Não, pois embora possa haver questões religiosas, culturais etc., a vacina deve ser tratada como uma questão de saúde pública e coletiva. Isso torna todas as pessoas seguras. Quanto aos efeitos colaterais, eles são raros e em soma, quando comparado os efeitos aos benefícios é melhor tomar a vacina do que ficar doente. 
Figura 7: Estrutura do argumento do aluno A12

\begin{tabular}{l}
\hline$\underline{\text { Dados (D) }}$ \\
Dado que: \\
- Torna todas as pessoas seguras; \\
É melhor tomar a vacina do que ficar \\
doente. \\
-Quanto aos efeitos colaterais, eles \\
são raros e em soma, quando \\
comparado os efeitos aos benefícios. \\
\hline
\end{tabular}

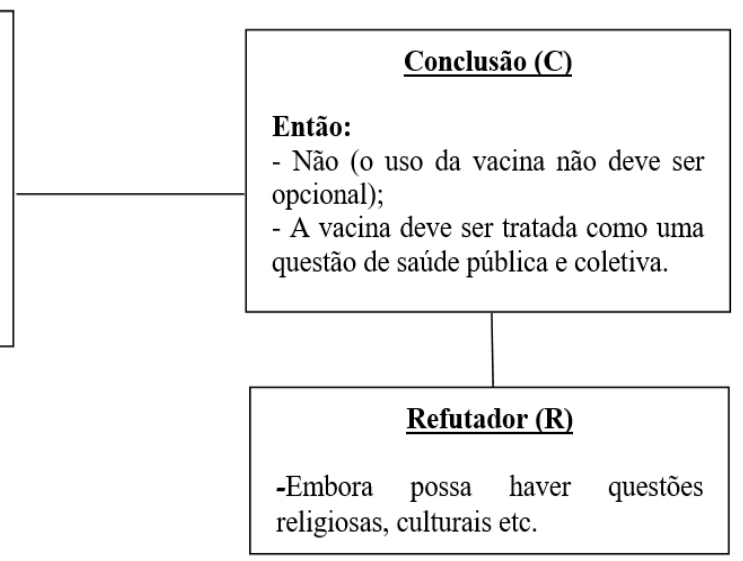

Fonte: Elaborada pelos autores.

A exemplo do argumento de A12, os demais alunos desse grupo, de forma consistente, levaram em conta os aspectos da coletividade, o qual é fundamental quando se pensa na questão da vacinação.

No Grupo 3, se inserem os alunos que não apresentaram uma justificativa concreta sobre a opcionalidade ou não da vacinação (11,8\%). Quanto ao conteúdo dos argumentos, os alunos apresentam nas suas conclusões que a questão individual versus social entra em embate para que as pessoas tomem suas decisões.

A11, por exemplo, apresenta no seu dado a vacinação como processo individual e público, isso faz com que o aluno não saiba opinar sobre a opcionalidade do uso da vacina.

A11. Na verdade, eu não sei optar. Essa questão envolve práticas individuais e públicas, as pessoas são projetadas a pensar de acordo como foram criadas ou informadas. Cabe a cada um se informar se o que se tem de conhecimento é verídico, para assim defender com justificativos fortes suas ideias. 
Figura 8: Estrutura do argumento do aluno A11

Dados (D)
Dado que:
- Essa questão envolve práticas individuais e
públicas;
-As pessoas são projetadas a pensar de
acordo como foram criadas ou informadas;
- Cabe a cada um se informar se o que se tem
de conhecimento é verídico, para assim
defender com justificativos fortes suas ideias.

Fonte: Elaborada pelos autores.

Era de se esperar que os estudantes apresentassem argumentos com aspectos controversos, porque, como informado por Cunha e Garcia (2019), mesmo que relatos científicos se proponham a explicar os fenômenos no âmbito da saúde, os discursos divulgados nesses relatos concorrem com mitos, crenças populares e outras experiências sociais sobre a saúde e as enfermidades que são divulgados na atualidade, principalmente por meio de canais de informação online. Ainda assim, entende-se que as atividades serviram como uma ação para a Alfabetização Científica, em termos de educação em saúde, considerando-se que esse tipo de educação é promovida pela "combinação intencional de experiências de aprendizagem com objetivo de facilitar medidas comportamentais ou ações sobre os determinantes sociais da saúde a serem adotadas por pessoas, ou comunidades" (ASSIS, et al., 2010, p. 2).

\section{Considerações finais}

Os resultados evidenciam que a sequência de ensino por investigação apresentada neste trabalho fomentou discussões relevantes acerca da opcionalidade/ obrigatoriedade da vacinação em uma turma de $1^{\circ}$ ano do Ensino Médio, em aulas da disciplina Biologia. No entanto, mesmo tendo vivenciado as atividades ao longo da SEI, alguns alunos parecem não ter percebido o processo de vacinação como algo importante para a saúde da sociedade, e que o comportamento de defensores do movimento antivacinas pode comprometer um esforço historicamente construído pela ciência e por políticas públicas no sentido de garantir qualidade de vida e 
longevidade para a humanidade. Isso sugere que determinados aspectos da SEI precisam ser reformulados para que os alunos compreendam com mais profundidade as implicações da opção pela não vacinação, tanto para os indivíduos em particular, como para a sociedade. A inclusão de textos com opiniões de especialistas, por exemplo, poderá auxiliá-los a refletir sobre os movimentos antivacinas e pró vacinas e a pensar criticamente, do ponto de vista da ciência, sobre esse embate, de modo que identifiquem, sobretudo, as fragilidades de vários argumentos que circulam nas mídias.

Não negamos que os aspectos envolvidos na produção, armazenamento e manipulação das vacinas devam ser vistos de forma crítica, de modo a se considerar como estes podem resultar em efeitos adversos que venham a interferir na vida dos indivíduos. Há também que se levar em conta, ainda, que todo medicamento envolve efeitos colaterais e que a ponderação entre riscos e benefícios faz parte do processo de análise do seu uso.

A problemática da vacinação proposta pela SEI, por sua vez, vai além de uma questão pessoal, trazendo assim, uma discussão mais profunda, que requer argumentos que, para se tornarem bem elaborados necessitam de uma série de informações que se articulem como dados, garantias de inferências e conhecimentos de base consistentes. Nesse sentido, passou-se a refletir sobre como a SEI e seu desenvolvimento pode ser alterada de modo a garantir esse aspecto. Analisando criticamente a SEI nessa perspectiva, o nosso olhar recai sobre a importância do entendimento sobre dados epidemiológicos que explicitem a relação entre uso e não uso de vacinas e a disseminação de doenças. Isso provavelmente evidenciaria o quanto a decisão individual pelo uso ou não de vacinas repercute no coletivo. Tais dados, certamente, seriam elementos fundamentais para o aprofundamento da problemática proposta pela SEI, possibilitando uma melhor elaboração dos argumentos dos alunos sobre o tema abordado, evitando também que o professor de Biologia tenha que apresentar uma resposta final e decisiva para a questão de modo a suplantar o raciocínio crítico dos alunos. 


\section{Vaccine controversies: what do students think?}

\section{Abstract}

The vaccine is a milestone in the history of mankind, as its effectiveness has ensured that several diseases were eradicated. However, it is noticeable that the number of people seeking immunization has been declining, causing diseases, such as measles, to resurface. In order to engage students in practices that favor the process of scientific literacy, this work sought to analyze the construction of arguments elaborated by students of the 1st year of High School in Biology classes, through an investigative teaching sequence based on the vaccine theme, since themes involving the scientific and social approach show students how science and society integration occurs. Analyzing the students' oral speeches, the emergence of rich debates on the theme is evident. However, the written texts of some students suggest controversial arguments, in which rebuttals are completely opposed to conclusions. There were also arguments similar to those disclosed in information channels, in which vaccination is presented as an individual decision.

Keyword: Biology Teaching. Argumentation. Inquiry Teaching Sequence. Vaccines.

\section{Notas}

1 Reportagem do programa Domingo Espetacular (revista eletrônica da Rede Record), exibido originalmente em 06/08/2017 e disponível em https://youtu.be/GlOaGXP1tPI (último acesso em 08/12/2019).

2 Reportagem do Programa Fantástico, da Rede Globo de Comunicações, exibida originalmente na edição do dia 14/09/2014 e disponível em http:/g1.globo.com/fantastico/noticia/2014/09/governo-e-os-medicosgarantem-vacina-contra-hpv-e-segura.html (último acesso em 08/12/2019).

\section{Agradecimento}

Agradecemos à Capes pela bolsa e apoio financeiro.

\section{Referências}

ASSIS, S. S.; BORGES, J. N.; PAPOULA, N. R. P. R.; SANTIAGO, C. M. S.; TEIXEIRA, G. A. P. B. Educação em saúde - proposta de utilização de um modelo no ensino de ciências. Ensino, Saúde e Ambiente, v. 3, n. 2, p. 108-120, 2010. doi.org/10.22409/resa2010.v3i2.a21116

BRASIL. Ministério da Saúde. Portaria no 971, de 3 de maio de 2006. Aprova a política nacional de práticas integrativas e complementares (PNPIC) no sistema único de saúde. Diário Oficial da União: Seção 1, Brasília, DF, 2006, p. 20-5, 03 mai. 2006.

BRASIL. Manual de Normas e Procedimentos para Vacinação, Ministério da Saúde, Secretaria de Vigilância em Saúde, Departamento de Vigilância das Doenças Transmissíveis. - Brasília: Ministério da Saúde, 2014. 
CUNHA, S. E.; GARCIA, M. O tempo do medo versus o tempo da ciência: disputas discursivas sobre a epidemia de vírus Zika e microcefalia no Brasil. Comunicação e Sociedade, v. 35, p. 93-112, 2019. doi:10.17231/comsoc.35(2019).3133

DINIZ, M. O.; FERREIRA, L. C. S. Biotecnologia aplicada ao desenvolvimento de vacinas. Estudos Avançados, v. 24, n. 70, p. 19-30, 2010.

DRIVER, R.; NEWTON, P.; OSBORNE, J. Establishing the norms of scientific argumentation in classrooms. Science Education. v. 84, n. 03, p. 287-312, 2000. doi.org/10.1002/(SICI)1098237X(200005)84:3<287::AID-SCE1>3.0.CO;2-A

HOCHMAN, G. Vacinação, varíola e uma cultura da imunização no Brasil. Ciência \& Saúde Coletiva, v.16, n. 2, p. 375-386, 2011. doi.org/10.1590/S1413-81232011000200002

HODSON, D, Learning Science, learning about science, doing science: different goals demand different learning methods. International Journal of Science Education. v. 36, n. 15, 2014, p. 2534-2553. https://doi.org/10.1080/09500693.2014.899722

LEVI, G. C.; KALLÁS, E. G. Varíola, sua prevenção vacinal e ameaça como agente de bioterrorismo. Revista da Associação Médica Brasileira, v. 48, n. 4, p.357-362, 2019. http://dx.doi. org/10.1590/S0104-42302002000400045.

LÜDKE, M.; ANDRÉ, M. E.D.A. Pesquisa em educação: abordagens qualitativas. São Paulo: EPU, 1986.

PADILHA, A. S. C.; SUTIL, N.; MIQUELIN, A. F. Vídeos como recursos didáticos para a Aprendizagem Significativa de Ciências. In: CONGRESSO NACIONAL DE EDUCAÇÃO, 11., Curitiba. Anais [...]. Curitiba: PUCPR, 2013. p. 5214-5229.

PEDASTE, M.; MÄEOTS, M.; SIIMAN, L. A.; JONG, T.; RIESEN, S. A. N.; KAMP, E. T.; CONSTANTINOS, C. M.; ZACHARIA, Z. C.; TSOURLIDAKI, E. Phases of inquiry-based learning: Definitions and the inquiry cycle. Educational Research Review, v.14, p. 47-61, 2015. https:// doi.org/10.1016/j.edurev.2015.02.003

PONCE-BLANDÓN, J. A.; DÍAZ-RUIZ, M.; PABÓN-CARRASCO, M.; LOMAS-CAMPOS, M. El movimiento anti-vacunas como problema de salud pública: una revisión integrativa de la literatura. Revista de Enfermagem da UFSM, v. 8, n. 4, p. 812-828, 2018. http://dx.doi. org/10.5902/2179769229296

PORTO, M. Y. Uma revolta popular contra a vacinação. Ciência e cultura, v. 55, n. 1, p. 53-54, 2003.

PORTO, A.; PONTE, C. F. Vacinas e campanhas: as imagens de uma história a ser contada. História, Ciências, Saúde-Manguinhos, v. 10, p. 725-742, 2003.

RATZ, S. V. S.; MOTOKANE, M. T. A construção dos dados dos argumentos em uma sequência didática investigativa em ecologia. Ciência \& Educação, v. 22, n. 4, p. 951-973, 2016. doi. org/10.1590/1516-731320160040008.

ROCHA, J. A.; SILVA, A. C. T. Compreensões de alunos de nível médio sobre descoberta: discussões em torno do episódio da descoberta da radioatividade em uma sequência de ensino e aprendizagem. Investigações em Ensino de Ciências, v. 24, n. 2, p. 56-71, 2019.

SADLER, T. Situated learning in Science education: socio dcientific issues as contexts for practice. Studies in Science Education. v. 45, n.1, p. 1-42, 2009. doi.org/10.1080/03057260802681839 
SANCHES, S. H. D. F. N.; CAVALCANTI, A. E. L. W. Direito à saúde na sociedade da informação: a questão das fake news e seus impactos na vacinação. Revista Jurídica, v. 4, n. 53, p. 448-466, 2018.

SANTOS, V. C.; EL-HANI, C. N. Fazer Ciência, Abordar Questões Sociocientíficas: Diferentes objetivos demandam diferentes participações discursivas. In: XI ENCONTRO NACIONAL DE PESQUISA EM EDUCAÇÃO EM CIÊNCIAS,11., Florianópolis. Anais. [...].Florianópolis: UFSC, 2017. p. 1-10.

SANTOS, A. L. B.; MONTEIRO, C. M.; VARGAS, F. A. Papilomavírus humano: uma revisão narrativa da literatura. Revista Interdisciplinar em Ciências da Saúde e Biológicas, v. 2, n. 1, p. 61-76, 2018. http://dx.doi.org/10.31512/ricsb.v2i1.2628

SASSERON, L. H. Alfabetização científica, ensino por investigação e argumentação: relações entre ciências da natureza e escola. Ensaio Pesquisa em Educação em Ciências, v. 17. p. 49-67, 2015. http://dx.doi.org/10.1590/1983-2117201517s04.

SASSERON, L. H.; CARVALHO, A. M. P. Almejando a alfabetização científica no ensino fundamental: a proposição e a procura de indicadores do processo. Investigações em Ensino de Ciências, v.13, n. 3, p. 333-352, 2008.

SILVA, S. V.; SILVA JUNIOR, J. Mentiras sinceras (não) me interessam: estratégias biopolíticas do ministério da saúde no combate às fake News. Intersecções, v. 27, n.1, p. 226-246, 2019. https://revistas.anchieta.br/index.php/RevistaInterseccoes/article/view/1395

TEIXEIRA, M. Z. Homeopatia nas doenças epidêmicas: conceitos, evidências e propostas. Revista de Homeopatia, v. 73, n. 1, p. 36-56, 2010.

TOLEDO, A. C. C. História da Varíola. Revista Médica de Minas Gerais, v. 15, n. 1, p. 58-65, 2005.

TOULMIN, D. E. Os usos do argumento. São Paulo: Martins Fontes, 2006.

TRIVELATO, S. F. L.; TONIDANDEL, S. M. R. Ensino por investigação: eixos organizadores para sequencias de ensino de biologia. Ensaio Pesquisa em Educação em Ciências. v.17, p. 97-114, 2014. doi.org/10.1590/1983-2117201517s06.

VIEIRA, R. D.; NASCIMENTO, S. S. A argumentação em sala de aula de física: limites e possibilidades de aplicação do padrão de Toulmin. In: NASCIMENTO, S. S.; PLANTIN, C. (Org.) Argumentação e o ensino de ciências. Curitiba: Editora CRV, 2008. 